\title{
Building Community Resilience Using Gain-Loss Framing to Nudge Homeowner Mitigation and Insurance Decision-making
}

\author{
Mengtian Zhao \\ University of Southern California \\ jessicazhaomt@gmail.com
}

\begin{abstract}
Promoting homeowners' preparation for natural disasters is a critical component of building community resilience. Adoption of protective actions by individual homeowners could reduce the risk of injury and damage to property; however, despite extensive public education programs, numerous studies report that households still are underprepared for natural disasters. The effectiveness of gain-loss framing to nudge risk averse decisionmaking has been demonstrated across several domains, yet the application of gain-loss framing effects for natural disaster preparation has concentrated only on policy-level decisions. A behavioral experiment $(N=1,840)$ was conducted to test whether gain-loss framing can be used to nudge homeowner risk mitigation and insurance purchase decisions. Consistent with Prospect Theory, results indicate that a gain-frame is more likely to lead to risk averse decisions to mitigate for floods and hurricanes, but not for earthquakes. Disaster specific framing effects for nudging individual mitigation decisions provide unique implications building community resilience.
\end{abstract}

\section{Introduction}

In the United States, natural and climate-related disasters caused over $\$ 1$ trillion in damage costs since 1980 [1] Even one single severe weather event could result in massive destruction; for example, the 2011 Joplin tornado caused 158 direct fatalities, and approximately $\$ 3$ billion in economic losses [2]. Voluminous research has been conducted on the topic of natural hazards preparation. Broadly, three categories of preparation methods are used by civic emergency organizations: warning messages, evacuations, and adoption of protective measures. Warning messages and evacuations can help reduce casualties, financial loss and injuries resulting from a natural disaster [3], and extensive research has been conducted to evaluate the characteristics of warning messages and evacuation decisions. Detailed discussion of warning messages and evacuations are

\author{
Richard S. John \\ University of Southern California \\ richardj@usc.edu
}

beyond the scope of this project; for a thorough review of warning messages, see [4], and for a detailed summary of evacuation research, see [5]. Another important component of risk management is to encourage residents susceptible to natural disasters to adopt protective measures (such as storing food and water or household retrofitting). Therefore, understanding how individuals make decisions when facing natural disasters can help emergency planners better allocate resources and aid in the development of more effective communication strategies.

It is often assumed that providing civilians with more detailed information about hazards and mitigation alternatives would encourage protective action and reduce disaster-related damages [6,7]; however, previous literature has demonstrated that this assumption is ill-founded in the context of natural disaster preparation $[8,9,10]$. In one study, New Zealand residents susceptible to volcanic hazards demonstrated poor knowledge of risk mitigation behaviors related to volcano eruptions, even after multiple local campaigns about volcano hazards had been conducted [11]. Furthermore, the authors reported that knowledge about mitigation behavior did not correlate with the adoption of protective actions. Similarly, many studies also reported that adoption of protective actions remained low, despite considerable efforts on public natural disaster education [12,13,14].

Some scholars have proposed that the lack of successful adoption of mitigation measures might be linked to anticipated future beliefs and feelings $[15,16,17]$. For example, surveyed homeowners in New Zealand were more likely to take protective action if they believe that preparing for earthquakes would improve living conditions and property values, reduce damage to homes, and minimize disruption to daily life [18]. Others suggested that cognitive bias also plays an important role in homeowners' decisions to mitigate natural disaster related risks. For example, projection bias refers to a tendency for the decision maker to anchor beliefs about her feelings in the future based on her feelings at the moment. In the context of natural disaster mitigation, since mitigation decisions are typically made in advance before a disaster occurs, 
the decision maker might underestimate the likelihood of encountering the disaster in the future and the potential trauma the disaster can bring, which makes the decision maker reluctant to invest in risk mitigation methods [19,20].

The objective of our research is to investigate whether manipulation of the decision frame for taking protective action influences the likelihood of adopting mitigation measures in the context of natural hazards.

\section{Cognitive Systems Underlying Decision Making Processes}

In recent years, cognitive scientists have proposed two distinctive cognitive systems underlying decisionmaking processes $[21,22,23,24]$. System 1 thinking deals with behaviors that are more instinctive and automated, often times the thought process of System 1 is unconscious, and only the final product of System 1 thinking is reflected in behavior. For example, driving to work every day does not require deliberation on every single step along the way; cognitive systems can quickly and automatically retrieve previous experience to guide completion of the task [25]. Conversely, System 2 thinking governs thoughts that are more abstract and require more deliberation [26]. For example, if an unexpected traffic accident occurs, System 2 thinking will step in and consider alternative plans - will this delay my arrival time? should I take a detour to avoid traffic? Psychologists who support the dual-process thinking systems argue that System 2 thinking provides an evolutionary advantage as it can adjust to unexpected or novel information from the environment [27].

The intertwined System 1 and System 2 thinking can efficiently help navigate daily life; however, the unique nature of natural hazards poses a unique challenge for the cognitive system. Compared to typical day-to-day decisions, for most people natural disasters are infrequent and unfamiliar, therefore more difficult to draw upon past experiences, thereby impeding System 1 thinking. What complicates the decision even more is that in the realm of natural disasters, relying on previous experiences may lead to highly suboptimal decisions, resulting in catastrophic consequences.

In the case of Hurricane Katrina, residents reported that one of the top reasons for not evacuating was previous experience of surviving less severe hurricanes unharmed without evacuation [28]. Furthermore, decision-making related to natural hazards is complex in that engaging in mitigation activities may impact many aspects of daily life and may involve a substantial uncertainty. As an example, consider a family that just purchased a home in
Southern California. The new home is located at a seismic hazard zone, and the family needs to decide whether to invest $\$ 5,000$ in retrofitting their new home or not. Southern California has not incurred a severe, large scale earthquake since the 1994 Northridge Earthquake. If the goal of this family is to minimize future risk, retrofitting would be the ideal, utilitymaximizing solution. However, the decision becomes much more complicated when considering associated realistic uncertainties, such as:

1. It is unclear when and where will the next big earthquake strike,

2. They may be spending money in preparing for nothing,

3. The cost of retrofitting could be invested in other ventures that might improve the overall welfare of the family,

4. Retrofitting is only effective for a certain time period,

5. What if they invested in a project that can protect their property for 10 years and the disaster occurred at year 11 ?

In decision theory, it is often assumed that a rational person would choose the optimal option to maximize her expected interests when all the probabilities and consequences are known for each available alternative [23,29]. However, this assumption is rarely met in real life, and may be even less likely to hold when making decisions related to natural hazards. Past behavioral research suggests that when facing such difficult, high-stake decisions without sufficient information, people often resort to relying on cognitive heuristics as shortcuts. Cognitive heuristics, as defined by [30], refer to judging a target by attribute(s) that come more readily to mind, while ignoring other information that is more difficult to retrieve. Since heuristics require less cognitive effort, they are quite challenging to counter [31]. Moreover, heuristics possess ecological validity in some cases and can be used to aid decision making.

In their pioneering book Nudge [32], Thaler and Sunstein proposed the concept of "choice architecture", which refers to the act of organizing the context in which the decision is made so that the optimal option for the decision maker appears more appealing, thereby helping decision makers choose better options. Using choice architecture to promote better decisions has been studied extensively in the health domain [33,34]; however, nudging individual decisions for natural disaster mitigation by manipulating choice architecture has not been investigated empirically.

The current project focuses on utilizing one particular manipulation of choice architecture, gainloss framing, as a way of nudging people to adopt 
protective actions. The following section provides a conceptual introduction to gain-loss framing, a review of previous empirical research on gain-loss framing effects, and a framework for applying gain-loss framing in the context of natural hazard preparation.

\section{Gain-Loss Framing Effects in the Context of Natural Disasters}

Gain-Loss framing effects first originated from Kahneman and Tversky's concept of a reference point in Prospect Theory [35]. A decision frame is defined as the "conception of acts, outcomes, and contingencies" associated with the decision maker's choice. Prospect Theory provides an account for understanding decision making processes involving risks, and postulates that for a decision under uncertainty, when potential losses or negative consequences of a decision are emphasized (defined as a loss frame), people tend to be risk-seeking, whereas when the potential benefits of positive consequences of a decision are emphasized (defined as a gain frame), people tend to be risk averse [35].

Tversky and Kahneman [36] tested this hypothesis with a hypothetical Asian disease scenario, in which respondents are told that a rare Asian disease is about to strike and kill 600 people in the US. Two programs have been proposed to combat the disease. If the first program is chosen, 200 people will be saved for sure; if the second program is chosen, there is a $1 / 3$ probability 600 people will be saved and 2/3 probability that no one will be saved. The same problem was then described in different wording. If the third program is chosen, 400 will die for sure; however, if the last program is chosen, there's a $1 / 3$ probability that no one will die and $2 / 3$ probability that 600 people will die. Respondents were asked to choose between two treatments.

In all four descriptions, the expected number of people who die is 400; therefore, respondents should either choose the sure thing option (200 people will be saved for sure or 400 will die for sure) in both frames or the gamble (where probabilities are involved) in both frames if gain-loss framing effects don't impact decision making. If respondents are risk averse, they should pick the sure thing option in both frames; if respondents are risk seeking, they should pick the gamble in both frames. However, results showed that respondents were more risk-averse when outcomes are framed as lives saved, and more risk-seeking when outcomes are framed as lives lost, providing preliminary empirical support for a gain-loss framing effect.

We can also evaluate the Asian Disease Problem by visiting the value function for Prospect Theory. In
Prospect Theory, the value function of a particular choice is defined as losses and gains from the status quo. In the Asian Disease Problem discussed above, the status quo is the implied reference point for the loss frame. As seen on Figure 1, the value function of Prospect Theory is S-shaped: concave in the gain domain and convex in the loss domain. This asymmetry captures the effects of gain-loss framing on people's risk preferences. In the case of the Asian Disease problem, reference point $\mathrm{O}$ represents the status-quo, where no one is harmed and there's no outbreak of the disease. Since the number of people saved is 200 across all programs, one can think of A as the amount of people saved and A' as the amount of people lost. Point B represents the perceived value of saving 200 people when presented with a gain-framed message, and point $\mathrm{C}$ represents the perceived value of saving 200 people when presented with a loss-framed message. Since the value function for the loss domain is steeper than the value function for the gain domain, the perceived value for saving 200 people with a gainframed program is lower compared to the perceived value of saving 200 people with a loss-framed program, nudging people to be risk averse when presented with gain-framed messages, and risk seeking when presented with loss-framed messages.

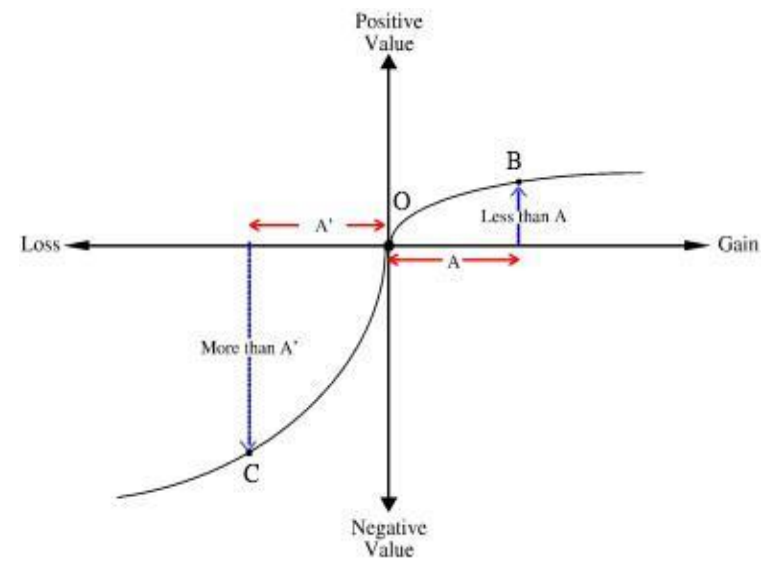

Figure 1. Value function from Prospect Theory

\section{Mitigation Behavior vs. Insurance}

Since mitigation behavior is also generically referred to as protective actions, protective measures, precautionary behaviors, etc., homeowners' mitigation behavior is defined as any physical remediation of the property recommended by emergency management authorities (such as the local and federal government, National Weather Service, FEMA, etc.) that could mitigate risks associated with 
natural hazards. In the natural disaster preparation literature, the primary focus is encouraging and improving mitigation behavior.

Although insurance plays a vital role in ensuring financial protection in the aftermath of natural disasters in developed countries such as the US [37], the uncertainty associated with natural disaster insurance makes it challenging for people to adopt. First, the process of both the insurance company and insured individual(s) gathering information about the opposite party is quite taxing. Second, the uncertainty surrounding the impact of a natural hazard makes it challenging for civilians to choose among the many available insurance plans. Third, homeowners may resort to taking mental shortcuts and relying on heuristics when making an insurance purchase [38,39]. For example, amnesia bias (the tendency of making decisions based only on recent experiences) and optimism bias (the tendency to underestimate the probability of a natural hazard or consequent financial losses) may cause residents who just experienced a natural disaster without incurring any financial loss to not renew an existing insurance policy [19,40]. Kunreuther characterized the challenges of mitigating natural disaster losses using insurance the term "natural disaster syndrome" [41], which refers to the combination of residents' limited interest in mitigating risk, and the high financial costs incurred by insurers and the federal government after a natural hazard strikes.

\section{Behavioral Experiment Methodology}

\subsection{Design Overview}

Two variables were manipulated: message frame (gain vs. loss) and risk mitigation (physical remediation vs. insurance purchase). Gain-loss framing is manipulated by shifting the reference point, and risk mitigation versus insurance purchase is manipulated by changing the scenario descriptions. Risk mitigation methods described in the decision vignettes were gathered from the NOAA's recommendations [42]. Respondents were randomly assigned into one of the four possible combinations of decision frame (gain vs. loss) and type of risk mitigation (physical remediation vs. insurance purchase).

\subsection{Decision Vignettes}

The decision vignette involves a hypothetical scenario of selling a home due to job re-location. In the case of hurricanes, since the property is located in a natural disaster-prone area and recent forecasts predicted an upcoming hazard on the way, the homeowner in this scenario faces the choice of whether or not to invest in storm shutters or hurricane insurance. The time-horizon for the mitigation decision is set at one-year, which allows specification of meaningful probabilities of loss from the hurricane hazard over a specific time period. This particular vignette allowed realistic manipulation of both risk mitigation strategy (physical mitigation vs. insurance) and frame (gain vs. loss).

In loss frame conditions, respondents faced two options: (1) spend a certain amount (on either retrofitting the property to be hazard-proof or purchasing an insurance for the hazard) on preparing for the upcoming hurricane season (which is the risk averse sure thing option), or (2) not spend any money and take their chances (which is the risk seeking gamble option). If they choose the gamble option, there's a probability that nothing happens to the property, and there's a chance that the hazard causes damages to the property requiring costly repairs. In the loss frame, the status quo is maintaining the current state as is, therefore any amount the participant decides to spend on preparing for hurricanes would be perceived as a loss. An example of the loss frame decision vignette for hurricanes for risk mitigation is provided in the Supplementary Materials, Part A.

The gain frame used the same scenario with the addition of one detail, namely, a new state regulation requires the seller to put a deposit in an escrow account to pay for any potential damages incurred before transferring the property to the new owner. In the gain frame, respondents faced two options, first, to invest a certain amount from the escrow account (for either retrofitting the property to be hazard-proof or purchasing an insurance for the hazard) and receive the remaining deposit back for sure (which is the risk averse sure-thing option), or to not spend any money and take their chances (which is the risk seeking option). If they choose the gamble option, there's a probability that nothing happens to the property and the deposit is returned in full, and there's a chance that the hazard causes damage to the property and none of the deposit is returned. In the gain frame, the status quo includes the expense of the required $\$ 10,000$ security deposit; therefore, any amount returned from the deposit would be perceived as a gain.

An example of the gain frame decision vignette for hurricanes for risk mitigation is presented in the Supplementary Materials, Part B. Analogous decision vignettes were constructed for both floods and earthquake mitigation. The order in which the two options (mitigate or not) were presented was randomized. 


\subsection{Gain-Loss Frame Manipulation}

Manipulation of gain-loss framing was achieved by shifting the reference point for a hypothetical mitigation decision, while keeping the expected value constant at -1000 (spending or losing $\$ 1,000$ ) across four conditions. For physical mitigation, the loss frame (which is more intuitive to consider) involves a choice between spending $\$ 1,000$ on installing storm shutters to prepare for the upcoming hurricane season, or to choose to gamble, in which there's a $90 \%$ probability of incurring no damage from hurricanes and a $10 \%$ probability of incurring damages worth of $\$ 10,000$. In the loss frame condition, the reference point is the status quo of maintaining everything as is; therefore, any amount invested on preparing for hurricanes would be perceived as a loss.

The gain frame used a slightly different description where the decision maker must first pay a $\$ 10,000$ security deposit in escrow; hence, any amount received back from the deposit would be perceived as a gain. Participants can either choose to use $\$ 1,000$ of the $\$ 10,000$ deposit to purchase storm shutters and receive the remaining $\$ 9,000$ back for sure, or to not invest in preparing for the upcoming hurricane season, in which there's a $90 \%$ probability of not incurring any damage and receive the entire deposit back, and a 10\% probability of incurring damage and no deposit is returned.

For insurance investments, the same manipulation was implemented and only the descriptions regarding hurricane shutters were changed to hurricane insurance. As an illustration, Figure 2 shows the four decision trees for each of the condition for the hurricane mitigation context.

Decision Tree for Risk Mitigation*Loss Frame Condition

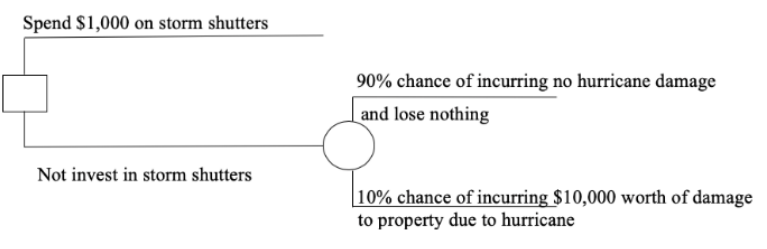

Decision Tree for Risk Mitigation*Gain Frame Condition

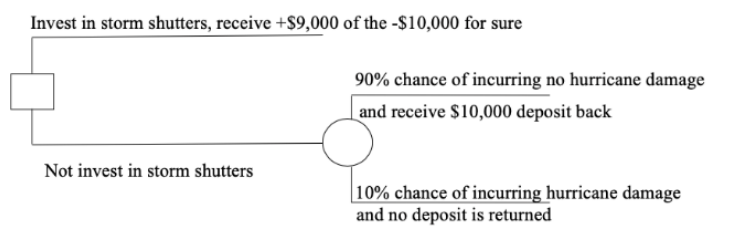

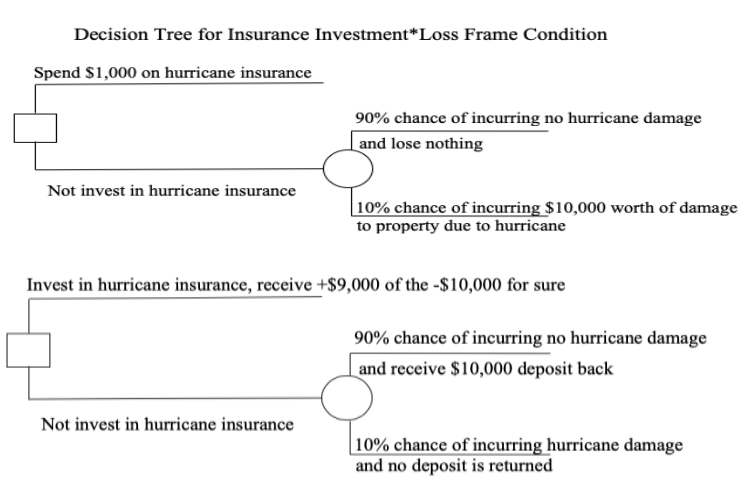

Figure 2. Decision trees for hurricane scenario

\subsection{Respondents}

Respondents were recruited from Amazon Mechanical Turk, and each worker received $\$ 0.55$ for participating in the survey. The survey took respondents on average 8 minutes to complete. Rouse found that when attention check questions are used, Turk workers provided more reliable scores [43], therefore one attention check question was included in each survey to filter out respondents who are not paying attention or respondents who are responding randomly. Respondents who failed the attention check question were excluded from analyses. Three different samples were collected for hurricane, flood and earthquake respectively. A power analysis [44] with power equal to or larger than 0.80 and sample size set to be sufficient enough to obtain a moderate effect size $(d=0.50)$ revealed that for a 2 by 2 factorial design, for each sample, each condition must have at least 50 respondents $(d=0.527)$. Therefore, the target population for each sample was set as 200 respondents.

For the hurricane sample, a total of 608 respondents (152 respondents in each condition) who currently live in one of the hurricane-prone states identified by the NOAA $[45,46]$ were recruited. For the flood sample, a total of 620 respondents (155 respondents in each condition) who currently live in one of the flood-prone states identified by the NOAA $[47,48]$. For earthquake sample, a total of 612 respondents (153 in each condition) who currently live in California were recruited. In all three samples, $<1 \%$ respondents were dropped due to failure to answer attention check questions correctly.

Across all three samples, the majority of respondents have previous experience with the disaster (with the earthquake sample reporting the highest percentage). The median age was 36 years and $55 \%$ were female. Approximately $2 / 3$ currently own their home (the rest were previous home owners or soon to be homeowners), and $90 \%$ had attended (or 
graduated) from college. The hurricane sample reported somewhat lower annual income and was more politically conservative compared to the earthquake and flood samples; the earthquake sample had fewer current homeowners compared to the other two samples. Details of the demographic variables for all three samples are provided in the Supplementary Materials, Part C.

\subsection{Measure of Objective Numeracy}

Since the decision problems used in this research all involve understanding numerical values and probabilities, objective numeracy was measured. Foundational numeracy skills are necessary for comprehending the risks associated with decisions, and previous research in medical decision making showed that low numeracy skills could impede comprehension of health statistics [49,50,51]. Objective numeracy was measured using a 7-item Cognitive Reflection Test (CRT7) [52].

Respondents answered seven open ended questions related to the construct of numeracy. For example, a bat and a ball cost $\$ 1.10$ in total; the bat costs a dollar more than the ball. How much does the ball cost? Scores for the CRT7 was computed by first coding whether each answer is correct or incorrect and then summing the scores. Each correct answer was coded as 1 and each incorrect answer was coded as 0 , making the total range of scores 0-7. Cronbach's alpha for the CRT7 was 0.72 in the original study [52], and Cronbach's alpha for the current study was estimated as $0.84,0.80$ and 0.78 for the earthquake, flood and hurricane samples, respectively. CRT7 correlates well with other objective measures of numeracy and was a significantly better predictor compared to either measures of intelligence or measures of executive functioning for rational thinking tasks. The measure of objective numeracy was included as covariates to account for group differences.

\subsection{Data Analyses}

A 2 by 2 (decision frame by mitigation context) logistic regression model with demographic variables included as predictors was used to evaluate the effects of gain-loss framing and mitigation versus insurance purchase on risk preferences. Gain-loss framing effects and mitigation vs. insurance purchase were coded as -0.5 and 0.5 using contrast coding, and the odds ratios obtained are therefore the average effects of both groups. The same data analyses procedure and coding were used for all three disaster samples.

Based on previous literature from Prospect Theory [35], we postulate that respondents assigned to loss frame vignettes tend to be risk-seeking and not select the mitigation option, whereas respondents assigned to gain frame vignettes will tend to be risk averse and would select the mitigation option.

\section{Results}

Figure 3 summarizes the percentage of respondents choosing the risk averse mitigation option for hurricanes. Of respondents assigned to physical remediation vignettes, $72.4 \%$ picked the risk averse option when the vignette is in gain frame, whereas $65.1 \%$ chose the risk averse option when the vignette is in loss frame. For respondents assigned to hurricane insurance purchase vignettes, $68.4 \%$ picked the risk averse option when the vignette is in gain frame, whereas $60.0 \%$ chose the risk averse option when the vignette is in loss frame. For both risk mitigation and insurance purchase, distributions of risk averse tendencies were consistent with the hypothesis that gain-frame messages are more likely associated with risk averse preferences.

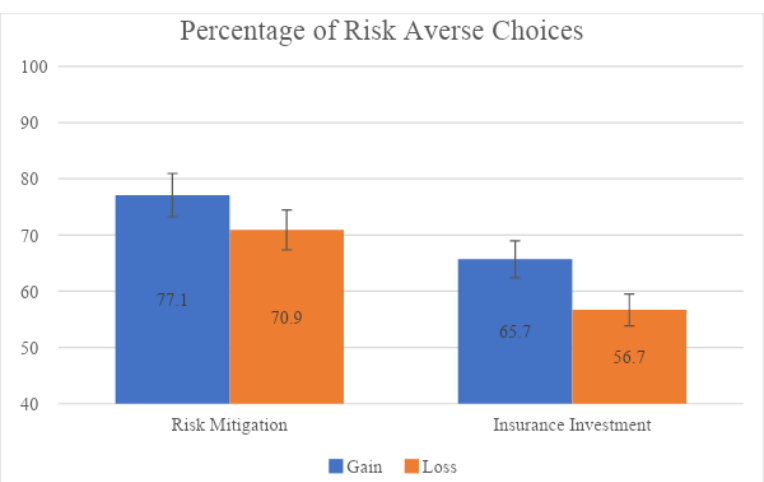

Figure 3. Percentage choosing the risk averse hurricane mitigation option by decision frame and mitigation context

Figure 4 summarizes the percentage of respondents choosing the risk averse flood mitigation option. A total of $87.7 \%$ of respondents assigned to risk mitigation vignettes picked the risk averse option when the vignette is in gain frame, whereas $73.4 \%$ chose the risk averse option when the vignette is in loss frame. For respondents assigned to flood insurance purchase vignettes, $77.7 \%$ picked the risk averse option when the vignette is in gain frame, whereas $75.0 \%$ chose the risk averse option when the vignette is in loss frame. For both risk mitigation and insurance purchase, distributions of risk averse tendencies were consistent with the hypothesis that gain-frame messages are more likely associated with risk averse preferences. 


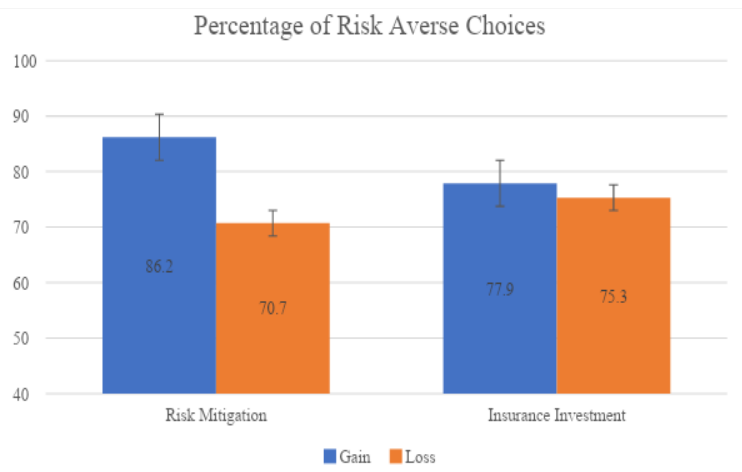

Figure 4. Percentage choosing the risk averse flood mitigation option by decision frame and mitigation context

Figure 5 summarizes the percentage of respondents choosing the risk averse mitigation option for hurricanes. Of all respondents assigned to risk mitigation vignettes, $65 \%$ picked the risk averse option when the vignette is in gain frame, whereas $71.9 \%$ chose the risk averse option when the vignette is in loss frame, contrary to the hypothesis that respondents will more likely choose the risk averse option when presented with gain-frame messages. For respondents assigned to earthquake insurance purchase vignettes, $64.6 \%$ picked the risk averse option when the vignette is in gain frame, whereas $50.9 \%$ chose the risk averse option when the vignette is in loss frame, consistent with the hypothesis that gain-frame messages are more likely associated with risk averse preferences.

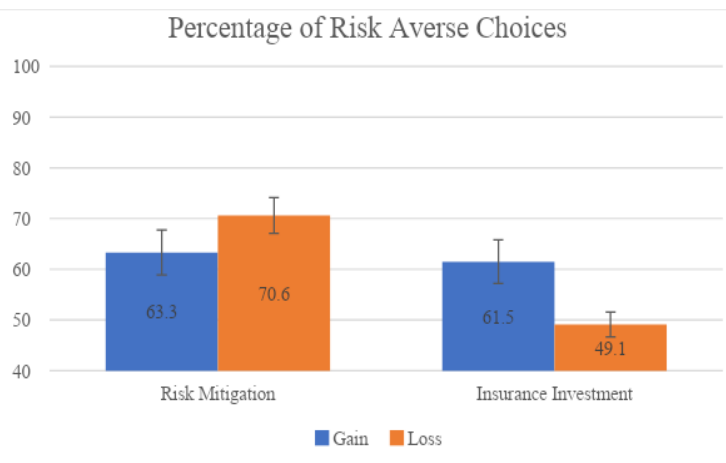

Figure 5. Percentage choosing the risk averse earthquake mitigation option by decision frame and mitigation context

Table 1 provides a summary of main and interaction effects from the three binary logistic regression predicting choices from the manipulation of decision frame and mitigation context, including predictors accounting for individual difference demographic variables. (Detailed results of all three regressions are presented in the Supplementary Materials, Parts D-F.) With respect to gain-loss framing effects, gain-loss framing yielded significant main effects for both floods and hurricanes, but gainloss framing did not impact risk averse tendencies for earthquakes. Respondents living in flood-prone states and hurricane-prone states are more likely to be risk averse when presented with gain-frame descriptions, however gain-loss framing failed to elicit significant changes in risk preference for the earthquake sample.

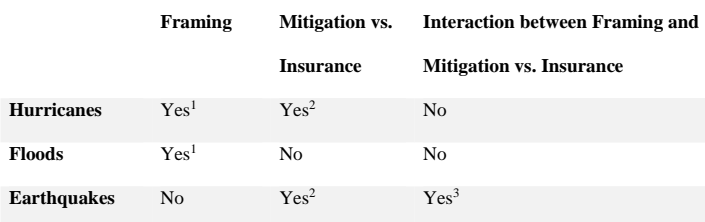

1: Gain frame was associated with stronger risk averse tendencies.

2: Risk mitigation was associated with stronger risk averse tendencies.

3: Mitigation versus insurance moderates the gain-loss framing effect: gain frame was associated with more risk averse tendencies for insurance purchase, but the opposite effect was observed for risk mitigation.

\section{Table 1. Summary of binary logistic regression model results for each disaster mitigation vignette.}

\section{Discussion}

Results demonstrate that gain-loss framing effects are effective in nudging people toward risk averse preferences for insurance purchases for all three natural disasters (floods, hurricanes and earthquakes), and for physical remediation investments for floods and hurricanes, but not for earthquake remediation. The lack of framing effect for earthquake mitigation might be a result of an overall disbelief in the efficacy of earthquake retrofitting measures. Results also suggest that respondents from earthquake and hurricane prone states are more likely to adopt retrofitting as a precaution measure, yet participants at risk for floods did not exhibit any preference for insurance vs. physical remediation. Overall, results from the current experiment offer insights for policy makers, suggesting that the effectiveness of gain-loss framing and preference for risk mitigation versus insurance purchase dependent on the disaster context.

With respect to risk mitigation versus insurance purchase, Table 1 indicates that participants at risk for hurricanes and earthquakes preferred to structurally 
mitigate than to purchase insurance, but this preference was not evident for residents at risk for floods. Specifically, respondents living in states that are at risk for hurricanes and earthquakes are more likely to select risk averse options when presented with risk mitigation options than insurance purchase options, yet no significant difference was observed for the flood sample. These results suggest that the preference of mitigating risk through structural retrofitting or purchasing insurance might be context dependent. The indifference toward flood insurance from respondents living in flood-prone states could potentially be explained by the lack of low cost and convenient insurance plans $[41,53]$.

Previous research in the realm of flood insurance have proposed various methods for designing an affordable and reliable insurance policy; however, private insurance agencies are not motivated to offer competitive flood coverage due to low market penetration, making the National Flood Insurance Program (NFIP) established by the U.S. government the only long-lasting widely available insurance plan for more than 40 years $[37,53,54]$. However, NFIP is only made available if the community where the decision maker currently resides in agree to adopt required flood mitigation and land use measures [37,53], whereas for earthquakes and hurricanes, numerous insurance plans are available on the market without the requirement of community participation $[55,56]$. This finding points to the need for flood insurance education campaigns and the importance of providing more diversified flood insurance options.

Regarding the interaction between gain-loss framing and preparation context, Table 1 indicates that only the earthquake context yielded a significant interaction between framing and risk mitigation versus insurance purchase, however no main effects of framing and risk mitigation versus insurance were detected. Results demonstrated that participants prone to seismic risks are more likely to be risk averse when presented with earthquake insurance options using gain-frames than loss frames. Intriguingly, the direction of effect for gain-loss framing is consistent with Prospect Theory for earthquake insurance purchases, but opposite for risk mitigation. For earthquake risk mitigation decisions, respondents are more likely to be risk averse under the loss frame than the gain frame. For earthquake insurance purchase decisions, respondents tend to be risk averse under the gain frame than the loss frame. Since gain loss framing effects were detected in predicted direction for hurricanes and floods in both mitigation and insurance investment context and for earthquakes only in insurance investment context, results indicate that earthquake mitigation measures might be different.

\section{Limitations and Future Research}

First, the mitigation decision vignettes are hypothetical. Although the decision vignettes used in the current study are realistic and results demonstrated the experimental manipulations were effective, there were no consequences following the respondents' decisions. The monetary consequences described in the scenarios were hypothetical and the gambles described were not resolved. Future research could explore whether incentivizing decisions impact risk attitudes.

Second, social stakeholder perceptions are theorized as one of the three core elements in the decision-making process of protective actions [57,58]. Social stakeholders involved in natural disaster preparation decisions are defined as authorities (government), emergency management agencies (such as National weather service), watchdogs (media, environmental groups), employers and households $[59,60]$. Social influences could come from psychologically closer sources than those provided in the current scenarios, such as neighbors, friends and family members. Households located in counties that require installation of hurricane shutters have shutters of significantly better quality [61]. Similarly, residents are much more likely to adopt earthquake prevention adjustments if other people are participating in such programs [62]. Therefore, future research could explore whether the psychological distance of social stakeholders plays a role in influencing people's willingness to mitigate risk. If at-risk populations are more likely to be influenced by social stakeholders they feel close to and trust, then policy makers could consider targeting specific neighborhoods and encourage residents to relay relevant information to family and friends to improve compliance with recommended protective actions.

\section{Conclusions}

This study provides empirical evidence regarding the effects of individual level gain-loss framing on mitigation and insurance purchase decisions for natural disasters. Findings from the experiment are meaningful because they:

1. Provide empirical evidence supporting the hypothesis that gain-loss framing effects previously reported at the policy or organizational level do generalize to gain-loss framing effects for individual and household decisions;

2. Demonstrate the generalizability and robustness of gain-loss framing effects across different natural disasters and both physical mitigation and insurance purchase decisions; 
3. Highlight the integral role of context dependency in framing mitigation decisions, indicating that policy makers should consider unique attributes of each natural disaster and tailor the decision frame accordingly in order to nudge individual decision makers to more prudent, riskaverse options.

\section{References}

[1] B. K. Paul, L. Emerson, V.T. Brock, \& S. Csiki, "Public response to tornado warnings: A comparative study of the May 4, 2003, Tornadoes in Kansas, Missouri, and Tennessee, Rep. No. 165," Natural Hazards Research and Applications Information Center, University of Colorado Boulder, Boulder, CO, 2013.

[2] S. Hoekstra, K. Klockow, R. Riley, J. Brotzge, H. Brooks, \& S. Erickson, "A preliminary look at the social perspective of warn-on-forecast: Preferred tornado warning lead time and the general public's perceptions of weather risks," Weather, Climate, and Society, 32, 128-140, 2011.

[3] J.H. Golden, \& C.R. Adams, "The tornado problem: Forecast, warning, and response," Natural Hazards Review, 12, 107-118, 2000.

[4] K.J. Tierney, M.K. Lindell, \& R.W. Perry, "Facing the unexpected: Disaster preparedness and response in the United States," Joseph Henry Press, Washington, D.C., 2001.

[5] J.H. Sorensen, B.M. Vogt, \& D.S. Mileti, "Evacuation: an assessment of planning and research, No. ORNL6376," Oak Ridge National Lab., TN, USA, 1987.

[6] M.K. Lindell, \& D.J. Whitney, "Correlates of household seismic hazard adjustment adoption," Risk Analysis, 20,1, 13-26, 2000.

[7] K. Smith, "Environmental hazards: Assessing risk and reducing disaster," Routledge, Abingdon, Oxon, UK, 2013.

[8] D.S. Mileti \& C. Fitzpatrick, "The causal sequence of risk communication in the Parkfield earthquake prediction experiment," Risk Analysis, 12,3, 393-400, 1992.

[9] J.P. Mulilis, T.S. Duval, \& R. Lippa, "The effects of a large destructive local earthquake on earthquake preparedness as assessed by an earthquake preparedness scale," Natural Hazards, 34, 357-371, 1990.

[10] J.P. Mulilis \& T.S. Duval, "Negative threat appeals and earthquake preparedness: a person-relative-to-event PrE model of coping with threat." Journal of Applied Social Psychology, 25(15), 1319-1339, 1995.

[11] D. Paton, L. Smith, \& D. Johnston, "Volcanic hazards: risk perception and preparedness," New Zealand Journal of Psychology, 29(2), 86-91, 2000.

[12] M. Ballantyne, D. Paton, D. Johnston, M. Kozuch, \& M. Daly, "Information on volcanic and earthquake hazards: The impact on awareness and preparation," Institute of Geological and Nuclear
Sciences Report, No. 2, Institute of Geological and Nuclear Sciences, Lower Hutt, 2000.

[13] J. McClure, F. Walkey, \& M. Allen, "When earthquake damage is seen as preventable: Attributions, locus of control and attitudes to risk," Applied Psychology, 48(2), 239-256, 1999.

[14] M.K. Lindell \& D.J. Whitney, "Correlates of household seismic hazard adjustment adoption," Risk Analysis, 20(1), 13-26, 2000.

[15] J.K. Doyle, G.H. McClelland, W.D. Schulze, S.R. Elliott, \& G.W. Russell, "Protective responses to household risk: A case study of radon mitigation," Risk Analysis, 11(1), 121-134, 1991.

[16] M.L. Edwards, "Social location and self-protective behavior: Implications for earthquake preparedness," International Journal of Mass Emergencies and Disasters, 11(3), 293-303, 1993.

[17] L.A. Russell, J.D. Goltz, \& L.B. Bourque, "Preparedness and hazard mitigation actions before and after two earthquakes," Environment and Behavior, 27(6), 744-770, 1995.

[18] D. McIvor \& D. Paton, "Preparing for natural hazards: normative and attitudinal influences," Disaster Prevention and Management: An International Journal, 16(1), 79-88, 2007.

[19] R.J. Meyer, "Why we under-prepare for hazards," In R. J. Daniels, D. F. Kettl, \& H. Kunreuther, Eds., On risk and disaster: Lessons from Hurricane Katrina, pp. 153173, University of Pennsylvania Press, Philadelphia, PA, 2006.

[20] H. Kunreuther, R. Meyer, \& E. Michel-Kerjan, "Overcoming decision biases to reduce losses from natural catastrophes," In E. Shafir, Ed., The behavioral foundations of public policy, pp. 398-415, Princeton University Press, Princeton, NJ, 2013.

[21] J.S.B. Evans, "In two minds: dual-process accounts of reasoning," Trends in Cognitive Sciences, 7(10), 454459, 2003.

[22] D. Kahneman, \& P. Egan, "Thinking, fast and slow Vol. 1," Farrar, Straus and Giroux, New York, 2011.

[23] K.E. Stanovich, \& R.F. West, "Individual differences in reasoning: Implications for the rationality debate?" Behavioral and Brain Sciences, 23(5), 645665, 2000.

[24] K.E. Stanovich \& R.F. West, 2011.

[25] K.E. Stanovich \& R.F. West, "On the relative independence of thinking biases and cognitive ability," Journal of Personality and Social Psychology, 94(4), 672, 2008.

[26] A. Baddeley, "The episodic buffer: A new component of working memory?" Trends in Cognitive Sciences, 4(11), 417-423, 2000.

[27] J.J. Koehler, "The base rate fallacy reconsidered: Descriptive, normative, and methodological challenges," Behavioral and Brain Sciences, 19(1), 117, 1996.

[28] K. Elder, S. Xirasagar, N. Miller, S.A. Bowen, S. Glover, \& C. Piper, "African Americans' decisions not to evacuate New Orleans before Hurricane Katrina: A qualitative study," American Journal of Public Health, 97(Supplement_1), S124-S129, 2007. 
[29] A. Tversky, \& D. Kahneman, "Rational choice and the framing of decisions," Journal of Business, S251S278, 1986.

[30] D. Kahneman, \& S. Frederick, "Representativeness revisited: Attribute substitution in intuitive judgment," In T. Gilovich, D. Griffin, \& D. Kahneman, Eds., Heuristics and biases, pp. 49-81. Cambridge University Press, New York, 2002.

[31] G. Gigerenzer, \& W. Gaissmaier, "Heuristic decision making," Annual Review of Psychology, 62, 451-482, 2011.

[32] R.H. Thaler, \& C.R. Sunstein, "Nudge: Improving decisions about health, wealth, and happiness," Penguin, 2009.

[33] T.M. Marteau, D. Ogilvie, M. Roland, M. Suhrcke, \& M.P. Kelly, "Judging nudging: can nudging improve population health?" BMJ: British Medical Journal Online, 342, 2011.

[34] B.R. Handel, "Adverse selection and inertia in health insurance markets: When nudging hurts," American Economic Review, 103(7), 2643-82, 2013.

[35] D. Kahneman, \& A. Tversky, "Prospect Theory. An analysis of decision making under risk," Econometrica, 47, 263-291, 1979.

[36] A. Tversky \& D. Kahneman, "The framing of decisions and the psychology of choice," Science, 211(4481), 453-458, 1981.

[37] E. Michel-Kerjan, \& H. Kunreuther, "Redesigning flood insurance," Science, 333(6041), 408-409, 2011.

[38] P.A. Raschky, \& H. Weck-Hannemann, "Charity hazard-A real hazard to natural disaster insurance?" Environmental Hazards, 74, 321-329, 2007.

[39] P. Picard, "Natural disaster insurance and the equityefficiency trade-off," Journal of Risk and Insurance, 75(1), 17-38, 2008.

[40] R. Meyer \& H.C. Kunreuther, "The ostrich paradox: Why we underprepare for disasters," Wharton Digital Press, Philadelphia, 2017.

[41] H. Kunreuther, "Mitigating disaster losses through insurance," Journal of Risk and Uncertainty, 122(3), 171-187, 1996.

[42] NOAA https://www.noaa.gov/topic-tags/naturaldisasters.

[43] S.V. Rouse, "A reliability analysis of Mechanical Turk data," Computers in Human Behavior, 43, 304-307, 2015.

[44] J. Cohen, "Statistical power analysis for the behavioral sciences," 2nd ed., Lawrence Erlbaum, Hillsdale, NJ, 1988.

[45] J. Jarrell, M. Mayfield, E. Rappaport, \& C. Landsea, "The deadliest, costliest, and most intense United States hurricanes from 1900 to 2000 and other frequently requested hurricane facts," pp. 1-29, NOAA Technical Memorandum NWS TPC-3, Miami, FL, 2001.

[46] C. Landsea, "How many direct hits by hurricanes of various categories," TCFAQ E19, 2018. Retrieved April 23, 2019, from https://www.aoml.noaa.gov/hrd/tcfaq/E19.html

[47] K.A. Dahl, E. Spanger-Siegfried, A. Caldas, \& S. Udvardy, "Effective inundation of continental United
States communities with 21 st century sea level rise," Elementa Science of the Anthropocene, 5, 37, 2017.

[48] L. Garfield, "Flood-prone US states have billions of dollars of property at stake in the next 15 years - here's where it will be worst," 2018, Retrieved from https://www.businessinsider.com/us-states-climatechange-flooding-risk-2018-7

[49] L.M. Schwartz, S. Woloshin, W.C. Black, \& H.G. Welch, "The role of numeracy in understanding the benefit of screening mammography," Annals of Internal Medicine, 127(11), 966-972, 1997.

[50] S. Woloshin, L.M. Schwartz, S. Byram, B. Fischhoff, $\&$ H.G. Welch, "A new scale for assessing perceptions of chance: a validation study," Medical Decision Making, 203, 298-307, 2000.

[51] M.M. Schapira, S.L. Davids, T.L. McAuliffe, \& A.B. Nattinger, "Agreement between scales in the measurement of breast cancer risk perceptions," Risk Analysis, 24(3), 665-673, 2004.

[52] M.E. Toplak, R.F. West, \& K.E. Stanovich, “Assessing miserly information processing: An expansion of the Cognitive Reflection Test," Thinking \& Reasoning, 20(2), 147-168, 2014.

[53] M.J. Browne, \& R.E. Hoyt, "The demand for flood insurance: empirical evidence," Journal of Risk and Uncertainty, 20(3), 291-306, 2000.

[54] E.O. Michel-Kerjan, "Catastrophe economics: the national flood insurance program," Journal of Economic Perspectives, 24(4), 165-86, 2010.

[55] M.F. Grace, R.W. Klein, \& Z.J. Liu, "Increased hurricane risk and insurance market responses," Journal of Insurance Regulation, 24(2), 332, 2005.

[56] H. Kunreuther, \& A.E. Kleffner, "Should earthquake mitigation measures be voluntary or required?" Journal of Regulatory Economics, 4(4), 321-333, 1992.

[57] M.K. Lindell \& R.W. Perry, "Communicating environmental risk in multiethnic communities, Vol. 7," Sage Publications, 2003.

[58] M.K. Lindell \& R.W. Perry, "The protective action decision model: theoretical modifications and additional evidence," Risk Analysis, 32(4), 616-632, 2012.

[59] K.D. Pijawka, \& A.H. Mushkatel, "Public opposition to the siting of the high-level nuclear waste repository: The importance of trust," Review of Policy Research, 10(4), 180-194, 1991.

[60] J.T. Lang, \& W.K. Hallman, "Who does the public trust? The case of genetically modified food in the United States," Risk Analysis, 25(5), 1241-1252, 2005.

[61] W. G. Peacock, "Hurricane mitigation status and factors influencing mitigation status among Florida's singlefamily homeowners," Natural Hazards Review, 4(3), 149-158, 2003.

[62] D.S. Mileti, \& J.D. Darlington, "The role of searching in shaping reactions to earthquake risk information," Social Problems, 44(1), 89-103, 1997. 